\title{
CVBEM and FVM Computational Model Comparison for Solving Ideal Fluid Flow in a 90-Degree Bend
}

\author{
Colin Bloor ${ }^{1 *}$, Theodore V. Hromadka II², Bryce Wilkins ${ }^{2}$, Howard McInvale ${ }^{2}$ \\ ${ }^{1}$ Senior Consultant, Hromadka \& Associates, Rancho Santa Margarita, USA \\ ${ }^{2}$ Department of Mathematical Sciences, United States Military Academy, West Point, New York, USA \\ Email: ‘cbloor25@gmail.com, tedhromadka@yahoo.com,bdwilkins95@gmail.com,doug.mcinvale@usma.edu
}

How to cite this paper: Bloor, C., Hromadka II, T.V., Wilkins, B. and McInvale, H. (2016) CVBEM and FVM Computational Model Comparison for Solving Ideal Fluid Flow in a 90-Degree Bend. Open Journal of Fluid Dynamics, 6, 430-437. http://dx.doi.org/10.4236/ojfd.2016.64031

Received: November 4, 2016

Accepted: December 26, 2016

Published: December 29, 2016

Copyright (c) 2016 by authors and Scientific Research Publishing Inc. This work is licensed under the Creative Commons Attribution International License (CC BY 4.0).

http://creativecommons.org/licenses/by/4.0/ (c) (i) Open Access

\begin{abstract}
While finite volume methodologies (FVM) have predominated in fluid flow computations, many flow problems, including groundwater models, would benefit from the use of boundary methods, such as the Complex Variable Boundary Element Method (CVBEM). However, to date, there has been no reporting of a comparison of computational results between the FVM and the CVBEM in the assessment of flow field characteristics. In this work, the CVBEM is used to develop a flow field vector outcome of ideal fluid flow in a 90-degree bend which is then compared to the computational results from a finite volume model of the same situation. The focus of the modelling comparison in the current work is flow field trajectory vectors of the fluid flow, with respect to vector magnitude and direction. Such a comparison is necessary to validate the development of flow field vectors from the CVBEM and is of interest to many engineering flow problems, specifically groundwater modelling. Comparison of the CVBEM and FVM flow field trajectory vectors for the target problem of ideal flow in a 90-degree bend shows good agreement between the considered methodologies.
\end{abstract}

\section{Keywords}

Complex Variable Boundary Element Method, Finite Volume Method, Ideal Fluid Flow, 90-Degree Bend, Computational Fluid Dynamics

\section{Introduction}

Finite volume methodologies have traditionally been used to analyse fluid flow problems, including groundwater models, through the use of computational fluid dynamics 
(CFD) software packages such as Fluent and OpenFOAM. And while various other domain modelling approaches are also common in fluid flow analysis, such as the finite element and finite difference numerical approaches, they are all limited by the necessity of a volume mesh, the characteristics of which can have a significant effect on both the accuracy and solution time of the computations [1]. Such difficulties can be overcome in groundwater flow models when the groundwater equipotentials are coupled with streamlines [2], an approach that is embedded in the complex variable boundary element method (CVBEM).

While the advantages of the CVBEM over domain modelling methods, such as FVM, are specifically described by Johnson et al. [3] and the CVBEM has been applied successfully to ideal fluid flow problems [4], this is the first such work in which the flow vectors are calculated directly from the CVBEM and compared to the results of a domain method. Specifically, a CFD computer program utilizing a finite volume methodology, known as EasyCFD, is used to develop a flow field vector outcome in a 90-degree bend which is then compared with a similar vector flow field outcome that is developed by the CVBEM.

Such a CVBEM vector flow field is a direct result of the CVBEM approximation function for the conjugate component. In addition, the vector flow field can be developed using vector gradients of the CVBEM potential function outcome, which has application to three-dimensional flow problems. What is particularly new, as presented in this paper, is the development of a procedure to develop stream function flow trajectory vectors based upon vector calculus gradients of the CVBEM potential function (that is, the real part of the CVBEM complex variable function outcome), as opposed to being based upon the CVBEM stream function (the imaginary part). Because the CVBEM solution solves the boundary value problem (BVP), the CVBEM flow trajectory vectors should properly represent the ideal fluid flow direction and magnitude of the flow regime. In other words, for the considered important ideal fluid flow application problem, the CVBEM solution should be the exact solution to the BVP and the produced fluid flow trajectory vectors should be correctly determined. The flow field vector outcome from EasyCFD is thus used to verify and validate the development of flow trajectory vectors by the CVBEM for ideal flow problems.

\section{Methodology and Software}

\subsection{Complex Variable Boundary Element Method (CVBEM)}

The CVBEM originates from the real variable Boundary Element Method (BEM) that was developed by Carlos Brebbia [5] [6]. In short, the CVBEM set of basis functions spans a vector space that is an element of the BVP solution being examined. This means that the CVBEM outcome is the solution to the BVP and not only satisfies the problem boundary conditions but it also satisfies the partial differential equation (PDE) of the governing Laplace equation. Because the CVBEM develops a well-defined function that applies throughout the problem domain (and also in the exterior of the problem domain), the flow field vector trajectories are calculated directly from the CVBEM 
approximation function rather than by the usual estimation of point values throughout the problem domain. Consequently, not only does the CVBEM develop an approximation function that solves the governing partial differential equations throughout the problem domain and in the exterior of the problem domain, but the stream line vector trajectories are derived directly from the CVBEM approximation function by either direct use of the conjugate function outcome or by use of vector gradient operation upon the CVBEM resulting potential function outcome. Further descriptions of CVBEM modelling and the mathematical underpinnings of the method can be found in several publications [7] [8]. Consequently, a rigorous examination of the CVBEM will not be repeated here.

\subsection{Finite Volume Method}

To develop the finite volume solution, the CFD software EasyCFD was used to setup and solve the 90-degree bend fluid flow model. EasyCFD is a CFD software tool for the numerical simulation of fluid flow in a boundary fitted mesh. The Navier-Stokes equations: mass, momentum, and energy, are solved via a finite volume methodology. Specific details and validation regarding the EasyCFD program can be found in several publications [9] [10].

\section{Test Problem Description}

The selected test problem is of two-dimensional ideal fluid flow in a 90-degree horizontal bend. This test problem has been the subject of several computational modelling assessments and is considered in the current work due to the availability of the analytic solution, and the challenge of developing the flow field vector trajectories for a highly spatially variable flow field problem. The CFD model used to simulate flow in a 90-degree horizontal bend is shown in Figure 1.

The modelling domain in which the results are compared is a square defined within the total modelling space as shown in Figure 1 (area of comparison), with vertices at $(0,0)(0,2)(2,2)(2,0)$. The square domain is the focus of all three outcomes for the vector field developments and comparisons. The area of comparison does not include the entire FVM model domain, as a portion of the domain was constructed to isolate the inlet and outlet, and the flow affects thereof, from the 90-degree bend, and thus cannot be assumed to replicate ideal flow in the 90-degree bend.

In order to directly compare the FVM results to the CVBEM application and the available analytic solution, it was necessary to approximate ideal flow in the FVM model. This was accomplished in EasyCFD by defining the fluid as water ( $\rho=1000$ $\mathrm{kg} / \mathrm{m}^{3}, \mu=0.001 \mathrm{~N}^{\star} \mathrm{s} / \mathrm{m}^{2}$ ), the flow type as laminar (to ignore turbulent effects), and the boundary walls as symmetry boundary conditions (i.e. slip-walls). The FVM solution was considered converged when all residuals ( $u, w$, mass) were less than $5 e-6$.

For the analytic solution, the mathematical description of the streamline function is directly available from the conjugate function of the complex variable monomial $\mathrm{w}(\mathrm{z})=$ $\mathrm{z}^{2}$ [8]. The CVBEM model results in the analytic solution function as well when the 


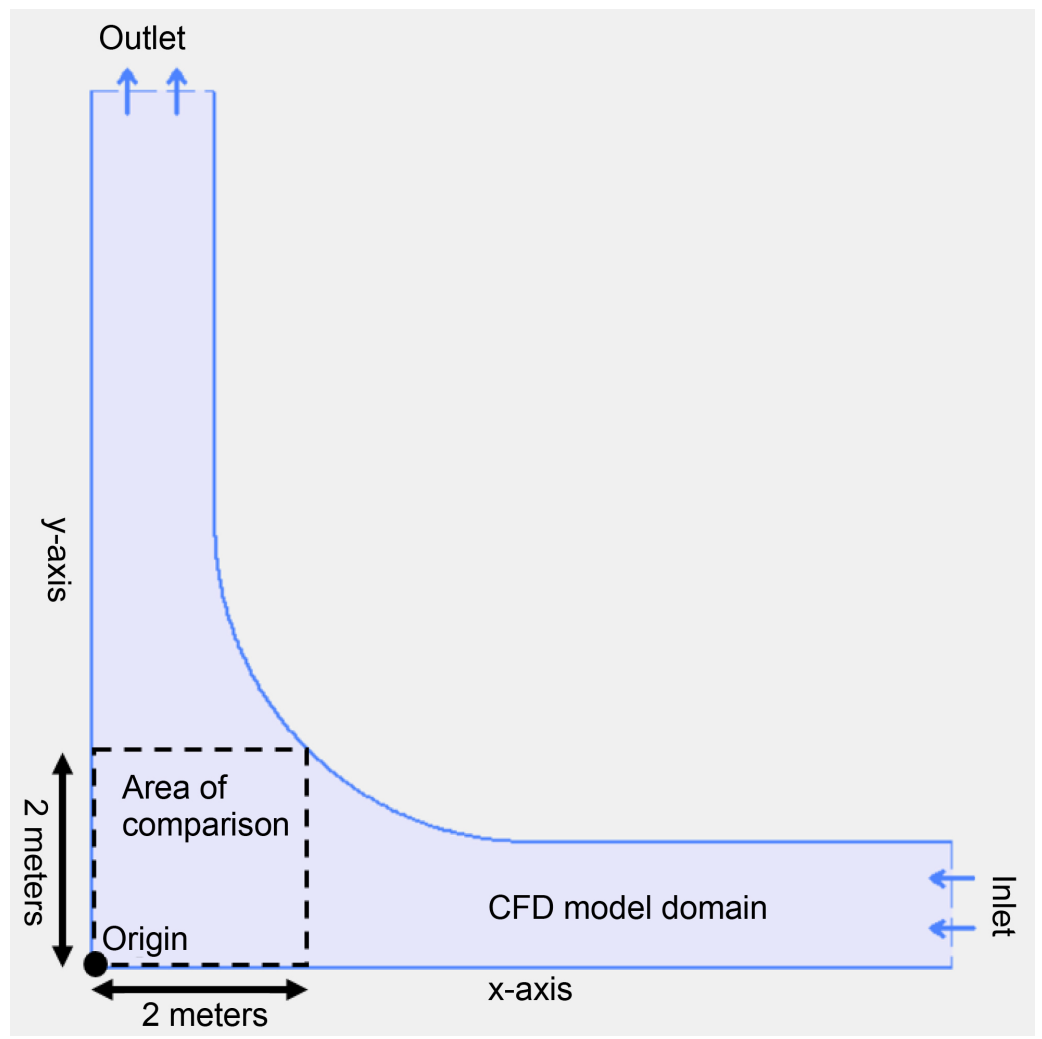

Figure 1. CFD model domain and area of comparison to CVBEM results.

CVBEM basis function specification includes complex variable monomials as well as the usual sums of products of complex polynomial and complex logarithm basis functions. Thus, three outcomes are available for comparison; namely, the FVM computational outcome of a set of highly discretized point estimates; the CVBEM approximation function outcomes; and the analytic solution.

\section{Flow Field Vector Trajectory Development}

For the CFD application, the flow field is developed by a finite volume computation that is made in addition to the usual post-processing interpolation of point estimates of fluid flow properties for the subject problem. For the analytic solution and the CVBEM outcome approximation function, flow field vectors are determined by direct use of the conjugates function or by application of the vector gradient operator upon the modelling outcome of the CVBEM approximation potential function. The CVBEM test problem solution can be seen in Figure 2.

\section{Results}

Comparisons of the vector trajectories between modelling approaches are displayed in Figure 3 and Figure 4. The FVM velocity vectors and streamlines are displayed in red, overlaid on the CVBEM potential isocontours and vector field. From Figure 3 and Figure 4, the flow field vector trajectories are seen to be in good qualitative agreement 


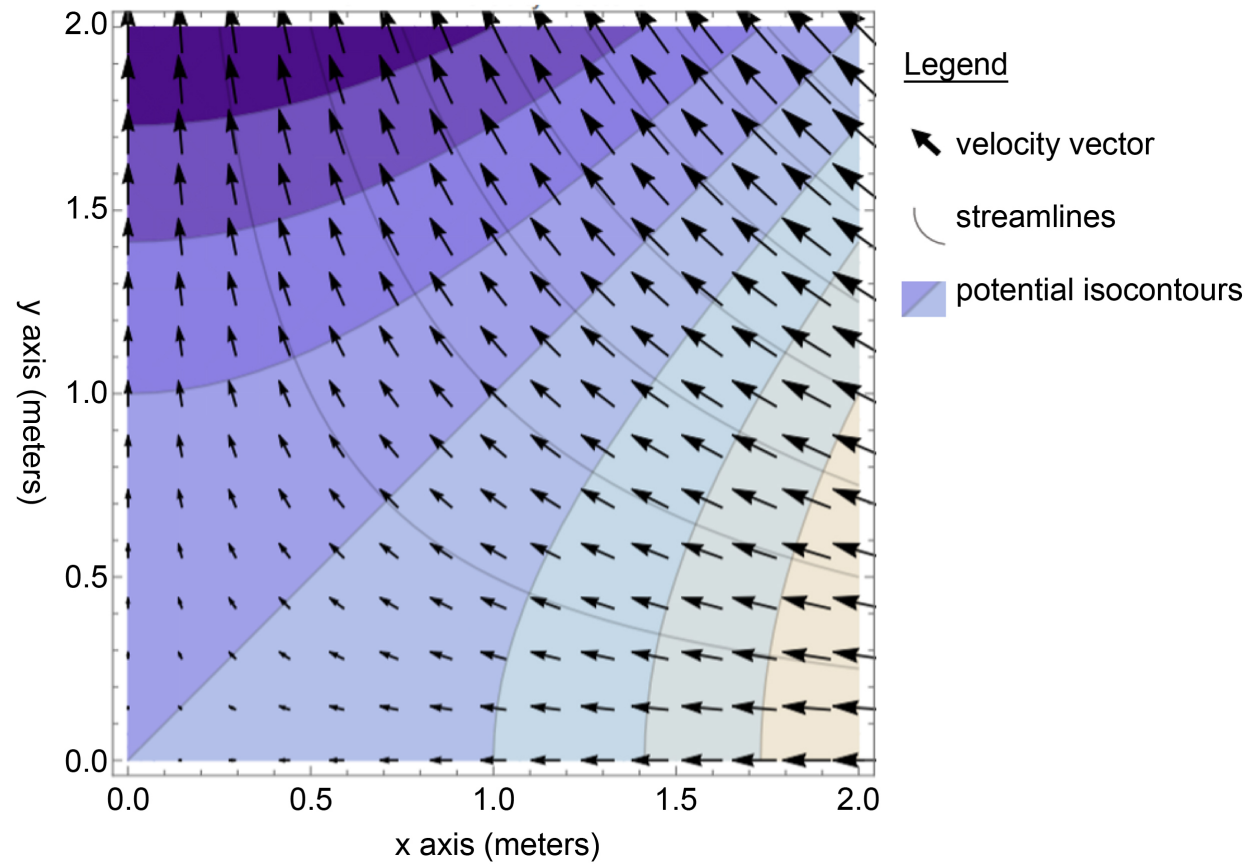

Figure 2. CVBEM problem domain with potential isocontours and velocity vector field.

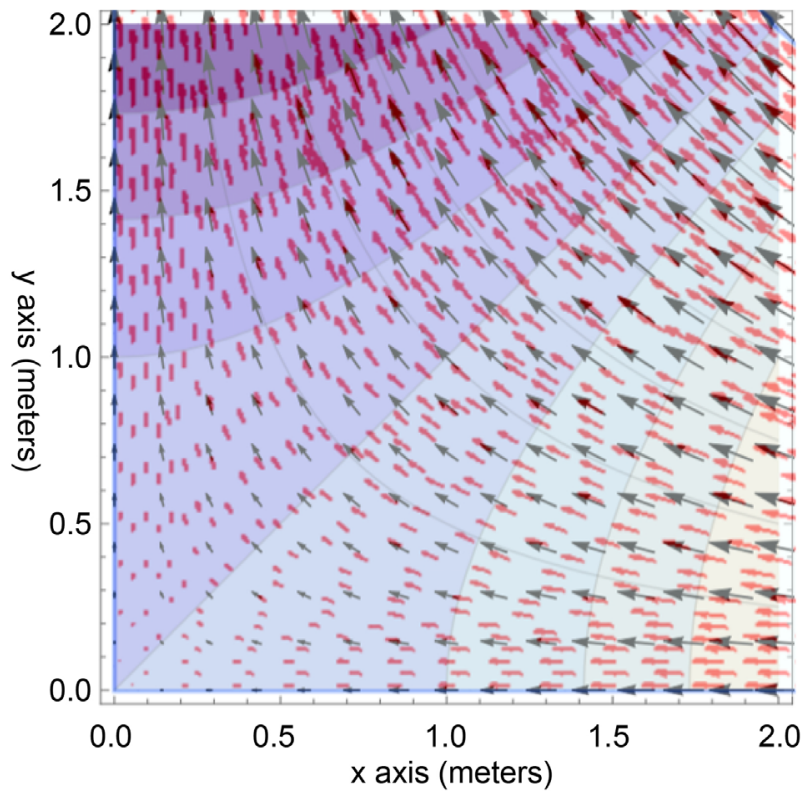

$\underline{\text { Legend }}$

CVBEM velocity vector

CVBEM streamlines

CVBEM potential isocontours

FVM velocity vector

Figure 3. Overlay of CVBEM velocity vectors on FVM model velocity vectors (size of vectors is not correlated between the two models).

as to vector direction for the considered FVM and CVBEM applications.

A quantitative comparison of the error between the 2 methods with respect to vector magnitude and direction can be found in Figure 5 and Figure 6. Each grid point represents a node in the model domain as determined by its coordinates. The colour of the box is an indication of the magnitude of the error, as determined by the difference 


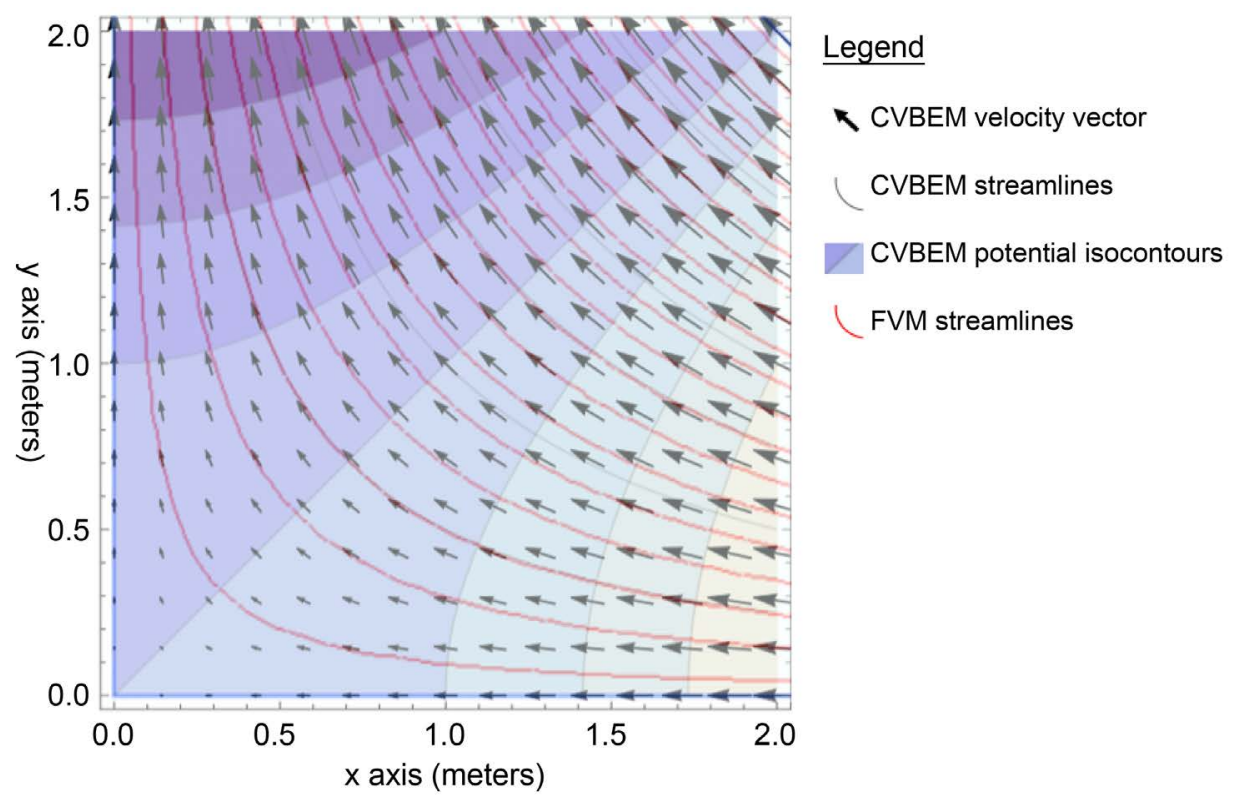

Figure 4. Overlay of CVBEM velocity vectors on FVM model streamlines.

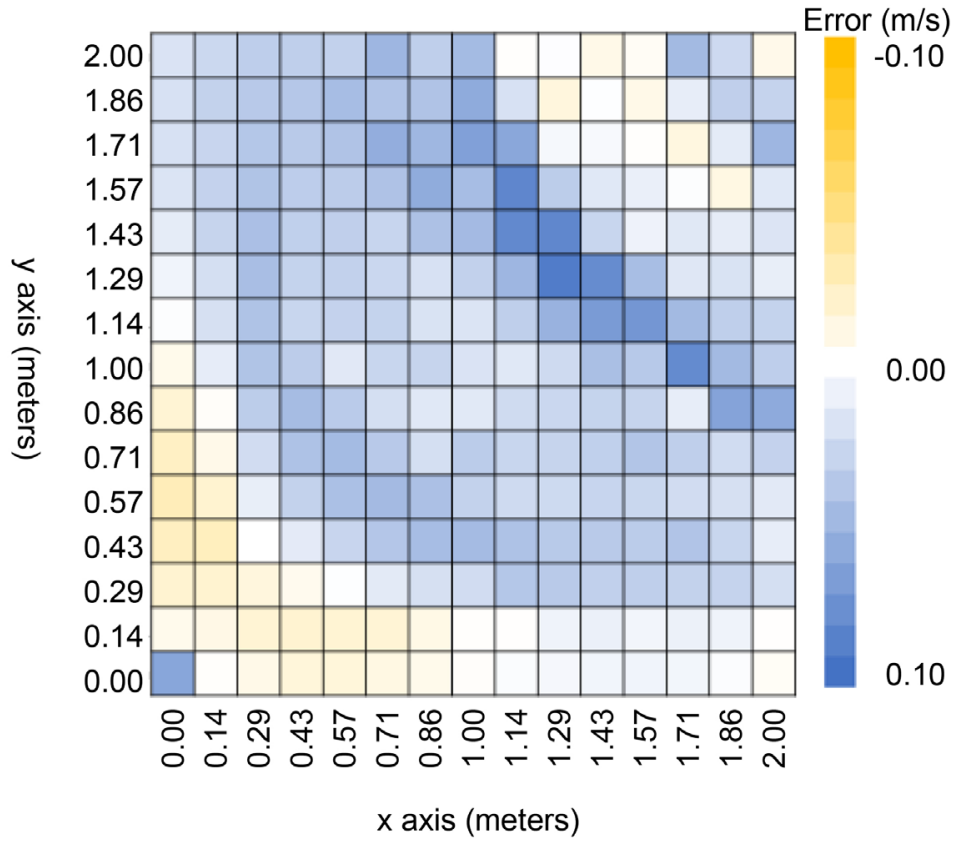

Figure 5. Error measurement of velocity magnitude of FVM model results as compared to CVBEM solution.

between the vector magnitude (Figure 5) or vector direction (Figure 6) between the CVBEM and FVM models. In Figure 5, a positive error indicates that the FVM model velocity vector was larger in magnitude than the CVBEM velocity vector, while the opposite is true for a negative error. In Figure 6, a positive error indicates that the FVM model velocity vector direction was at a larger angle than the CVBEM velocity vector, while the opposite is true for a negative error. For reference, a 0 -degree angle was 


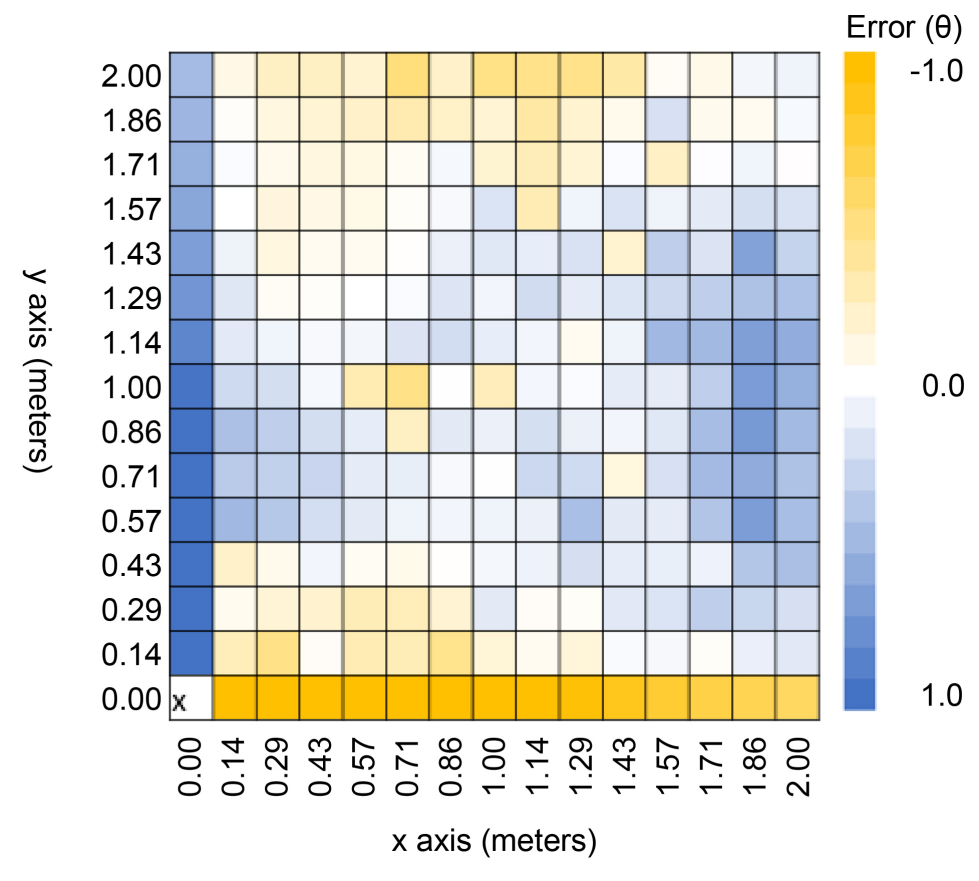

Figure 6. Error measurement of velocity vector angle of FVM model results as compared to CVBEM solution.

defined as a velocity vector pointing in the positive $\mathrm{x}$ direction with the angle increasing counter-clockwise.

The comparison of vector magnitudes shows that the maximum absolute error is less than $0.1 \mathrm{~m} / \mathrm{s}$, with an average absolute error of $0.03 \mathrm{~m} / \mathrm{s}$, or average relative error of $1.1 \%$. Similar agreement is found when comparing vector direction, which shows that the maximum absolute error is 10.1 degrees, with an average absolute error of 0.4 degrees. Even better agreement is found when comparing points not located along the $\mathrm{x}$ or $y$-axis ( 0.7 degrees maximum absolute error, $0.15 \%$ average relative error).

\section{Conclusion}

Comparison of the CVBEM and FVM flow field trajectory vectors for the target problem of flow in a 90-degree bend shows good agreement between the considered methodologies, achieving an average relative error of $1.1 \%$ in velocity magnitude and $0.15 \%$ in velocity direction. This is the first such work in which velocity vectors developed by the CVBEM are compared to the results from an FVM model and the results indicate that the flow trajectory vectors developed from the complex variable boundary element method are correctly determined and properly represent the ideal fluid flow velocity and direction.

\section{Acknowledgements}

The authors would like to thank the cadets and faculty of the United States Military Academy, Department of Mathematical Sciences, who provided invaluable feedback 
and support in development of this paper.

\section{References}

[1] Thornburg, H.J. (2012) Overview of the PETTT Workshop on Mesh Quality/Resolution, Practice, Current Research, and Future Directions. Proceedings of the 50 th AIAA Aerospace Sciences Meeting including the New Horizons Forum and Aerospace Exposition, Nashville, 9-12 January 2012, 0606. https://doi.org/10.2514/6.2012-606

[2] Rasmussen, T.C. and Yu, G.Q. (1997) Complex Variable Boundary Integral Modelling of Groundwater Flow and Transport. Proceedings of the 1997 Georgia Water Resources Conference, Athens, 20-22 March 1997, 379-382.

[3] Johnson, A.N., Hromadka II, T.V., Carroll, M., Hughes, M., Jones, L., Pappas, N., Thomasy, C., Horton, S., Whitley, R. and Johnson, M. (2014) A Computational Approach to Determining CVBEM Approximate Boundaries. Engineering Analysis with Boundary Elements, 41, 83-89. https://doi.org/10.1016/j.enganabound.2013.12.011

[4] Kendall, T.P., Hromadka II, T.V. and Phillips, D.D. (2012) An Algorithm for Optimizing CVBEM and BEM Nodal Point Locations. Engineering Analysis with Boundary Elements, 36, 979-984. https://doi.org/10.1016/j.enganabound.2011.11.008

[5] Brebbia, C.A. (1978) The Boundary Element Method for Engineers. Wiley, London.

[6] Brebbia, C.A. and Wrobel, L.C. (1979) Boundary Element Method for Fluid Flow. Advances in Water Resources, 2, 83-89. https://doi.org/10.1016/0309-1708(79)90015-0

[7] Hromadka II, T.V. and Chintu, L. (1987) The Complex Variable Boundary Element Method in Engineering Analysis. Springer, New York.

https://doi.org/10.1007/978-1-4612-4660-2

[8] Hromadka II, T.V. and Whitley, R. J. (2014) Foundations of the Complex Variable Boundary Element Method. Springer, New York. https://doi.org/10.1007/978-3-319-05954-9

[9] Lopes, A.M.G. (2010) A Versatile Software Tool for the Numerical Simulation of Fluid Flow and Heat Transfer in Simple Geometries. Computer Applications in Engineering Education, 18, 14-27.

[10] Lopes, A.M.G. (2016) A 2D Software System for Expedite Analysis of CFD Problems in Complex Geometries. Computer Applications in Engineering Education, 24, 27-38.

https://doi.org/10.1002/cae.21668 
Submit or recommend next manuscript to SCIRP and we will provide best service for you:

Accepting pre-submission inquiries through Email, Facebook, LinkedIn, Twitter, etc. A wide selection of journals (inclusive of 9 subjects, more than 200 journals)

Providing 24-hour high-quality service

User-friendly online submission system

Fair and swift peer-review system

Efficient typesetting and proofreading procedure

Display of the result of downloads and visits, as well as the number of cited articles

Maximum dissemination of your research work

Submit your manuscript at: http://papersubmission.scirp.org/

Or contact ojfd@scirp.org 